\title{
Severity of chest disease in cystic fibrosis patients in relation to their genotypes
}

\author{
L N Al-Jader, A L Meredith, H C Ryley, J P Cheadle, S Maguire, G Owen, \\ M C Goodchild, P S Harper
}

\begin{abstract}
A detailed comparison of the severity of chest disease with mutational status was carried out by cross sectional study of 127 cystic fibrosis patients, aged 1 to 31 years, living in Wales. Lung disease was classified according to severity, depending on pulmonary function tests (carried out on 76 patients) and chest radiograph status; information was obtained also on age at diagnosis in relation to severity of chest disease and colonisation with Pseudomonas species. Genotypes were determined by analysis for the mutations $\triangle F 508$, $\Delta 1507, G 551 D, R 553 X, G 542 X, R 117 H$, R560T, 1717-IG $>A$, and $621+1 G>T$.

CF patients homozygous positive and heterozygous for the $\Delta$ F508 deletion showed a significant decline of lung function with age. Unlike other studies, we did not find patients homozygous positive for the $\Delta F 508$ deletion to have poorer lung function compared with heterozygous patients. Patients with the genotype $621+$ IG $>$ T/ $\Delta$ F508 tended to have more severe chest disease than the $\Delta F 508$ homozygous patients in the same age group. There was some evidence that four patients heterozygous for $\mathrm{R} 117 \mathrm{H}$ have mild chest disease.

(f Med Genet 1992;29:883-7)
\end{abstract}

It has long been the impression of clinicians that cystic fibrosis (CF), the most common serious autosomal recessive genetic disorder in Caucasian populations, is heterogeneous, with variable system involvement and disease severity. ${ }^{1}$

Since the identification of the most common $\mathrm{CF}$ mutation, $\Delta \mathrm{F} 508,{ }^{2-4}$ and an increasing number of other mutations, comprehensive studies on phenotype/genotype comparisons have been published.5-8

Johansen $e t$ al carried out a cross sectional study of Danish CF patients and found that $\Delta$ F508 homozygous positive patients had poorer lung function and an increased incidence of chronic infection with Pseudomonas aeruginosa in comparison with heterozygous patients. They also found a significant correlation and decline in FEV 1 and FVC with age in the homozygous but not in the heterozygous patients.

Patients and methods

A cross sectional study was carried out on 127

CF patients living mainly in South Wales, age range 1 to 31 years. In order to exclude possible complicating factors associated with the presence of more than one affected subject in a family, patients who had sibs with CF (whether alive or dead) were excluded from the group analyses. However, two sets of sibs heterozygous for the $\mathrm{R} 117 \mathrm{H}$ mutation were examined separately. The age at diagnosis of $\mathrm{CF}$ (determined by clinical features and a positive sweat test) was noted.

Clinical classification of lung disease as 'mild' or 'moderate to severe' was carried out when patients were in a stable clinical state and depended on $\mathrm{FEV}_{1}$ (\% predicted) more or less than $75 \%$. Chrispin-Norman scores were calculated on all patients, whereby a lateral chest radiograph and the four quadrants of the lung fields on a posterior/anterior film were scored with regard to chest configuration and lung markings; a high score indicated a poor chest radiograph (maximum 38 points). ${ }^{9}$

Colonisation with Pseudomonas species was noted; patients were scored as positive if the organism was isolated even once, even though the infection was apparently not persistent. All parameters were assessed during the year before the analyses.

\section{GENOTYPE ANALYSES}

Data were sought for nine different mutations: $\Delta$ F508, $\Delta$ I507, 1717-IG > A, G551D, R553X, G542X, R560T, R117H, and $621+\mathrm{IG}>\mathrm{T}$. The $\Delta F 508$ deletion was identified by amplification of genomic DNA by polymerase chain reaction (PCR), followed by direct measurement of the size of the PCR product on a denaturing polyacrylamide gel. Multiplex PCR was used in some patients to screen simultaneously for five mutations (J P Cheadle, personal communication).

\section{STATISTICAL ANALYSES}

These were carried out using the $\chi^{2}$ test, Mann-Whitney U test, and Kruskal Wallis test as appropriate. For age dependent data, analyses were done in five year bands.

\section{Results}

SEVERITY OF CHEST DISEASE AS MEASURED BY FEV $_{1} \%$ PREDICTED

Data on $\Delta F 508$ status, $F_{1}$ and FVC ( $\%$ predicted) were available for 77 patients (table 1). A decline of respiratory function with age was shown in all three genotypes.

The median lines drawn for the values of $\mathrm{FEV}_{1} \%$ and $\mathrm{FVC} \%$ with age, shown in figs 1
Received 18 March 1992. Revised version accepted 4 June 1992. 
Table 1 Decline of FEV, and FVC \% of predicted with age in CF patients (number of patients in parentheses).

\begin{tabular}{|c|c|c|c|c|}
\hline \multirow[t]{2}{*}{$\Delta \mathbf{F 5 0 8}$} & \multicolumn{3}{|c|}{ Mean $\mathrm{FEV}_{1}, \mathrm{FVC}^{2} \%$ predicted } & \multirow[t]{2}{*}{ Total } \\
\hline & $5-9.9 y$ & $10-14.9 \mathrm{y}$ & $>15 y$ & \\
\hline 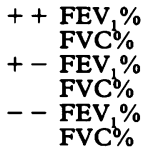 & 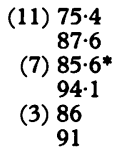 & $\begin{aligned} & \text { (11) } 69 \cdot 5 \\
& 86 \cdot 4 \\
& \text { (7) } 67 \cdot 6^{*} \\
& 85 \cdot 4 \\
& \text { (1) } 72 \\
& 78\end{aligned}$ & $\begin{array}{c}\text { (15) } 56 \cdot 7 \\
75 \cdot 7 \\
\text { (16) } 50 \cdot 4^{*} \\
64 \cdot 5 \\
\text { (5) } 43 \cdot 2 \\
54 \cdot 4\end{array}$ & $\begin{array}{r}(37) \\
(30) \\
(9)\end{array}$ \\
\hline
\end{tabular}

${ }^{*} \mathrm{p}<0.05$ (Kruskal Wallis test).

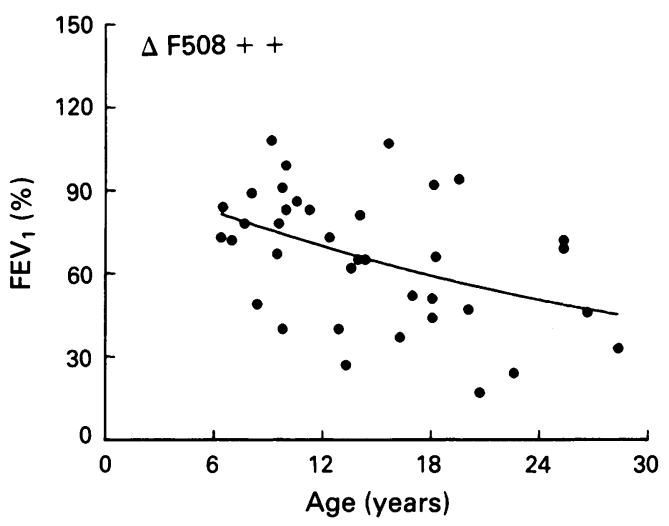

Figure 1 Median curve of $F E V, \%$ predicted, with age, for $\triangle F 508(++)$ patients.

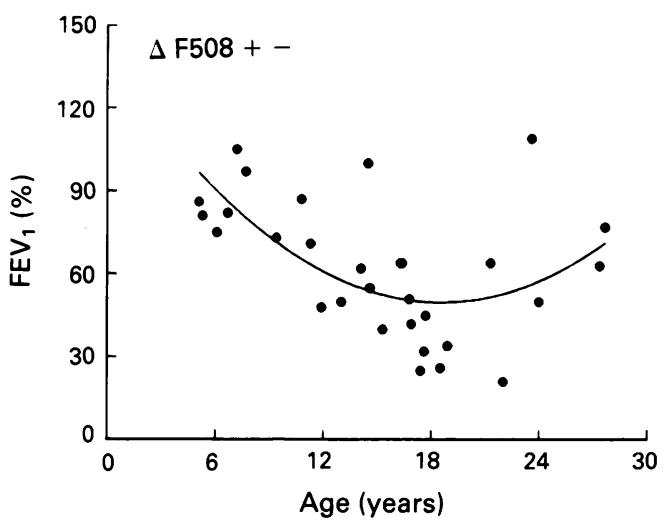

Figure 2 Median curve of FEV, \% predicted, with age, for $\triangle F 508(+-)$ patients.

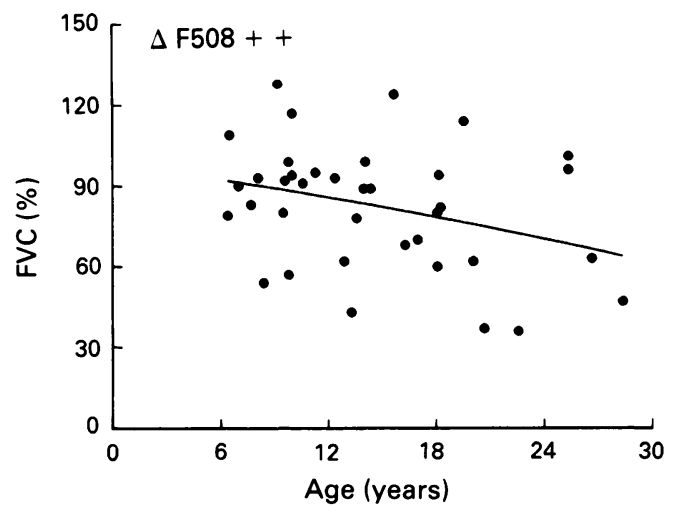

Figure 3 Median curve of FVC\% predicted, with age, for $\triangle F 508(++)$ patients.

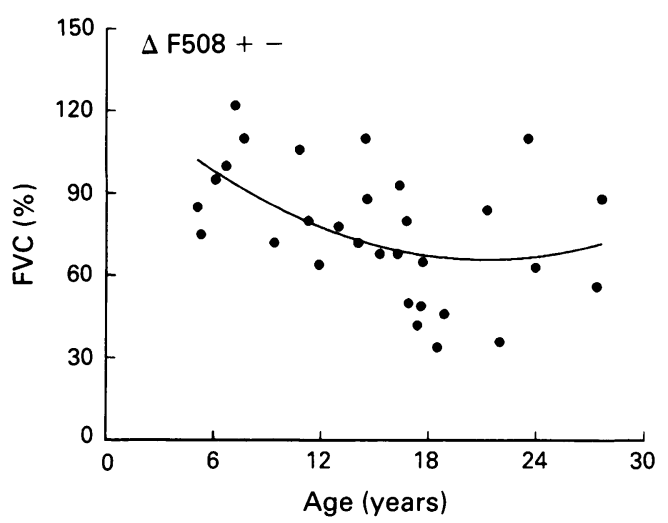

Figure 4 Median curve of FVC $\%$ predicted, with age, for $\triangle F 508(+-)$ patients.

to 4 for both homozygous positive and heterozygous $\Delta \mathrm{F} 508$ patients, have been fitted by a quadratic equation. $\mathrm{FEV}_{1} \%$ shows a significant linear correlation with age for both $\Delta \mathrm{F} 508$ $(++)(r=-0.43, p<0.01)$ and $\Delta F 508(+-)$ patients $(r=-0.39, \quad p<0.01)$. Similarly FVC\% shows a significant linear correlation with age for both $\Delta \mathrm{F} 508(++)(\mathrm{r}=-0.33$, $\mathrm{p}<0.05)$ and for $\Delta \mathrm{F} 508(+-)$ patients $(\mathrm{r}=-0.40, \mathrm{p}<0.01)$.

The five patients with $\Delta \mathrm{F} 508(+-)$ who contributed to the upturn in $\mathrm{FEV}_{1} \%$ at $>20$ years of age (fig 2) comprise two patients who carried G551D and three who were screened negative for the nine mutations analysed. These same five patients with $\Delta$ F508 (+-) contributed also to the upturn of the curve for FVC\% predicted (fig 4).

Among the nine patients who were homozygous negative for $\Delta \mathrm{F} 508$ (table 1) were: three with $621+\mathrm{IG}>\mathrm{T} /$ unknown mutation genotype (ages 6.3, 17.6, and 18 years; $\mathrm{FEV}_{1} \%$ predicted 80,30 , and 45 respectively); one with $\mathrm{G} 551 \mathrm{D} / 621+\mathrm{IG}>\mathrm{T}$ genotype (8 years, $\mathrm{FEV}_{1} 81 \%$ ); one with G551D/unknown mutation genotype (28 years, $\mathrm{FEV}_{1} \mathbf{7 7 \%}$ ); one homozygous for R553X (9 years, $\mathrm{FEV}_{1}$ 97\%); and three with unknown mutations $(14 \cdot 2,16 \cdot 7$, and 19.4 years; $\mathrm{FEV}_{1} \%$ predicted 72,28 , and 92 respectively).

\section{CHRISPIN NORMAN SCORE}

Values for Chrispin Norman scores were available for all 127 patients. Patients with $\Delta F 508$ $(++)$ and $(+-)$ showed a gradual, significant decline of these scores with age (table 2). The pattern of decline appeared to be somewhat different for the 12 patients who were $\Delta \mathrm{F} 508$ $(--)$, with a sharper deterioration at $>15$ years, but the small number precludes analysis.

\section{AGE AT DIAGNOSIS AND SEVERITY OF} CHEST DISEASE

Correlation coefficients were calculated between ages at diagnosis and $\mathrm{FEV}_{1} \%$ predicted at assessment, for both $\Delta \mathrm{F} 508$ homozygous positive and heterozygous patients, excluding not only sibs, but those who presented with meconium ileus or who were diagnosed after neonatal screening. Although there 
Table 2 Mean Chrispin Norman scores of CF patients in various age bands (number of patients in parentheses).

\begin{tabular}{|c|c|c|c|c|c|}
\hline \multirow[b]{2}{*}{$\Delta \mathrm{F} 508$} & \multicolumn{4}{|c|}{ Age bands (y) } & \multirow[t]{2}{*}{ Total } \\
\hline & $<5$ & $5-9.9$ & $10-14.9$ & $>15$ & \\
\hline $\begin{array}{l}++ \\
+- \\
--\end{array}$ & $\begin{array}{c}6^{*} \\
(25) \\
6 \cdot 9^{*} \\
(21) \\
5 \cdot 7 \\
(3)\end{array}$ & $\begin{array}{c}8 \cdot 7^{*} \\
(12) \\
6 \cdot 5^{*} \\
(8) \\
5 \\
(3)\end{array}$ & $\begin{array}{c}11 \cdot 5^{*} \\
(10) \\
11 \cdot 2^{*} \\
(7) \\
5 \\
(1)\end{array}$ & $\begin{array}{c}12.6^{*} \\
(16) \\
12.9^{*} \\
(16) \\
15.6 \\
(5)\end{array}$ & $\begin{array}{l}(63) \\
(52) \\
(12)\end{array}$ \\
\hline
\end{tabular}

${ }^{*} \mathrm{p}<0.05$ (Kruskal Wallis test)
$\Delta$ F508 homozygous positive and the five patients with $621+\mathrm{IG}>\mathrm{T} / \Delta \mathrm{F} 508$ genotype, in the 15 to 20 year age group, were 67.9 (SD 24.6) and 45.8 (SD 15.8) respectively. Chrispin Norman scores were a mean value of 11.0 (SD 6.1) for the eight $\Delta F 508$ homozygous positive patients and a poorer value of 13.8 (SD 5.0) for the patients with the $621+\mathrm{IG}>\mathrm{T} / \Delta \mathrm{F} 508$ genotype. Neither of these differences achieved statistical significance.

\section{R117H MUTATION}

was a tendency for $\Delta \mathrm{F} 508$ heterozygous patients to be diagnosed later in life, there was a wide overlap and age at diagnosis was not significantly different. There was no significant correlation between age at diagnosis and $\mathrm{FEV}_{1} \%$ predicted at assessment for either genotype.

\section{PSEUDOMONAS SPECIES COLONISATION}

OF THE LUNGS

No association was found between Pseudomonas species colonisation and $\Delta \mathrm{F} 508$ status of CF patients. Pseudomonas species were isolated from four $\Delta \mathrm{F} 508$ homozygous negative patients (ages $6 \cdot 1,16 \cdot 7,17 \cdot 6$, and 18.9 years) out of 12 patients with a similar genotype (mean age 11.9 (SD 6.4), age range 2.0 to 20.7 ). The incidence of Pseudomonas infection increased with age among all genotypes. Pseudomonas colonisation was significantly more common in patients with moderate to severe rather than mild lung disease, both among $\Delta$ F508 homozygous positive $\left(\chi^{2}=4 \cdot 30\right.$, $\mathrm{p}<0.05)$ and heterozygous patients $\left(\chi^{2}=7 \cdot 78\right.$, $\mathrm{p}<0.01)$.

$621+$ IG $>$ T MUTATION

There were 11 patients heterozygous for the 621 + IG > T mutation, of whom seven carried the $\Delta F 508$ mutation on the other chromosome. Among the remaining four patients with the $621+\mathrm{IG}>\mathrm{T}$ mutation, one patient carried G551D and three carried mutations so far not identified.

In an attempt to assess the severity of chest disease associated with the $621+\mathrm{IG}>\mathrm{T}$ mutation, comparisons were made between patients homozygous positive for $\Delta \mathrm{F} 508$ and patients with the $621+\mathrm{IG}>\mathrm{T} / \Delta \mathrm{F} 508$ genotype, in the same age group, with the use of $\mathrm{FEV}_{1} \%$ predicted and Chrispin Norman scores. FEV $\%$ was expressed as $>75 \%, 75$ to $50 \%$, and $<50 \%$ (table 3). Mean values for $\mathrm{FEV}_{1} \%$ predicted for the eight patients who were
Four CF patients from two families were heterozygous for the $\mathrm{R} 117 \mathrm{H}$ mutation. All were pancreatic sufficient and none had Pseudomonas species infection. In one family, the two CF sibs were heterozygous with $\Delta$ F508 deletion; ages were 16 and 8 years, values for FEV 1 were $80 \%$ and $97 \%$ predicted respectively, but Chrispin Norman scores were 12 and 8 respectively. In the other family, the CF sibs were heterozygous with G542X; ages were 4 and 3 years and Chrispin Norman scores 4 and 4.

The diagnosis of CF in the first family was made at the ages of 15 and 6 years, the 6 year old being diagnosed first on account of respiratory symptoms and her brother shortly afterwards, following sweat tests on the other sibs in this family. On review, he too had had mild respiratory symptoms. In the second family, the diagnosis followed neonatal screening in the younger sib, when the older, then aged 2 years, was confirmed to have CF also. He was found retrospectively to have had a false negative value for immunoreactive trypsin (IRT) on neonatal screening.

Thus for measurements of $\mathrm{FEV}_{1} \%$ predicted, the older sib pair belonged to our 'mild' group of chest disease patients, but even so their Chrispin Norman scores were appreciable. The younger pair was too young for lung function tests, but Chrispin Norman scores at 4 were somewhat lower than the mean score of 6.9 for the $\Delta \mathrm{F} 508$ heterozygous patients in the same age band (table 2 ).

\section{Discussion}

Chronic lung disease is the main clinical determinant of the course of $\mathrm{CF}$, which despite earlier diagnosis and considerably improved therapy still leads to death in adolescence and early adulthood in the majority of patients.

The identification of the most common CF gene defect, $\Delta F 508$, in September 1989 and 150 other gene deletions, mutations, and base

Table $3 F E V_{1} \%$ predicted in patients homozygous positive for the $4 F 508$ deletion in comparison with patients carrying the $621+I G>T / \Delta F 508$ genotype in different age bands.

\begin{tabular}{|c|c|c|c|c|c|c|c|c|c|c|c|c|c|}
\hline \multirow[b]{3}{*}{$\mathrm{FEV}_{1} \%$ predicted } & \multicolumn{12}{|c|}{ Age band (y) } & \multirow{3}{*}{ Total } \\
\hline & \multicolumn{3}{|c|}{$5-9.9$} & \multicolumn{3}{|c|}{$10-14.9$} & \multicolumn{3}{|c|}{$15-20$} & \multicolumn{3}{|c|}{$>20$} & \\
\hline & $>75$ & $75-50$ & $<50$ & $>75$ & $75-50$ & $<50$ & $>75$ & $75-50$ & $<50$ & $>75$ & $75-50$ & $<50$ & \\
\hline Genotype & \multicolumn{12}{|c|}{ No of patients } & \\
\hline $\begin{array}{l}\Delta \mathrm{F} 508(++) \\
\Delta \mathrm{F} 508 / 621+\mathrm{IG}>\mathrm{T}\end{array}$ & $\begin{array}{l}6 \\
2\end{array}$ & $\begin{array}{l}3 \\
0\end{array}$ & $\begin{array}{l}2 \\
0\end{array}$ & 5 & $\begin{array}{c}5 \\
\text { No patients }\end{array}$ & 2 & $\begin{array}{l}3 \\
0\end{array}$ & $\begin{array}{l}3 \\
2\end{array}$ & $\begin{array}{l}2 \\
3\end{array}$ & ${ }^{0} \mathrm{~N}$ & $\begin{array}{c}3 \\
\text { No patients }\end{array}$ & 4 & $\begin{array}{r}38 \\
7\end{array}$ \\
\hline
\end{tabular}


substitutions since, has provided the opportunity to study the relationship between CF phenotype and allelic heterogeneity at the CF locus.

This cross sectional study involved $127 \mathrm{CF}$ patients living in various parts of Wales, more than $50 \%$ of whom were from south Wales. Respiratory funrtion tests showed a significant decline of lung function with age for both $\Delta$ F508 $(++)$ and $(+-)$ patients. Although the shapes of these lung function curves were quite similar to those of Johansen et al, ${ }^{6}$ these authors did not find a significant decline in lung function tests among their heterozygous patients. From our data, we disagree with their conclusion that the homozygous patients necessarily have poorer lung function. In our study, the median lines for decline of FEV and FVC ( $\%$ predicted) correlated significantly with age, for both homozygous and heterozygous $\Delta \mathrm{F} 508$ patients. In both studies (that of Johansen et $a l^{6}$ and our study) an examination of $\mathrm{FEV}_{1} \%$ predicted for the $\Delta F 508$ heterozygous patients shows two populations at least: one population where lung function deteriorates severely with age and finally incapacitates the patients at around $\mathbf{1 6}$ to 20 years of age, and another population comprising the fitter, more mildly affected patients, contributing to the upturn in the curve. In the first population of the $\Delta F 508$ heterozygous patients in our study, a number of patients fell well below the $\mathrm{FEV}_{1} \%$ curve of median fit; among these were two patients heterozygous for $621+\mathrm{IG}>\mathrm{T}$, one patient heterozygous for G551D, and four who screened negative for the nine mutations analysed but who may carry one or more 'minor' mutations causing severe chest disease. The second population contributing to the upturn in the curve included five patients, of whom two carried G551D and three were screened negative for the nine mutations analysed.

A number of explanations could account for the upturn in the curve of median fit among the older heterozygous patients. This could relate to the death of the more severely affected patients and survival of a rather different group with an advantageous genotype; patients of different ages may have received different standards of treatment; or the shape of the curve could have been produced purely by a statistical fluctuation. It is not possible to say which of these factors, singly or in combination, is responsible. It may be relevant that one heterozygous female patient, who screened negative for the eight other mutations, died during the survey at 22 years with an $\mathrm{FEV}_{1}$ of $21 \%$ of predicted.

Graphs were not drawn for the $\Delta \mathrm{F} 508$ (- - ) patients because numbers were small; however, it was noted that five of these nine patients for whom respiratory function data were available showed a severe decline of lung function at more than 15 years of age. Among those five patients were one who carried (G551D/-) genotype with $\mathrm{FEV}_{1}$ of $77 \%$ and two who carried $(621+\mathrm{IG}>\mathrm{T} /-)$ genotype with $\mathrm{FEV}_{1}$ of $30 \%$ and $40 \%$ and two who screened negative for the nine mutations analysed, with $\mathrm{FEV}_{1}$ of $28 \%$ and $92 \%$.

As expected, there was a significant decline in Chrispin Norman scores with age among $\Delta \mathrm{F} 508(++)$ and $(+-)$ patients. Although the number of $\Delta \mathrm{F} 508(--)$ patients was small, the decline in these scores was more pronounced at 15 years of age and older. It could be argued that the $\Delta \mathrm{F} 508(--)$ patients have the genetic advantage earlier in life with well maintained respiratory function and a lesser need for aggressive treatment regimens and hospital admissions. However, they may lose this advantage as they grow older and as environmental factors which are known to influence chest disease have more cumulative effect, so causing the severe deterioration in pulmonary function at an older age. A 17 year old patient with $\Delta \mathrm{F} 508(--)$, whose $\mathrm{FEV}_{1} \%$ and FVC\% were $28 \%$ and $60 \%$ of predicted, died during the study.

In contrast to other studies, we did not find a significant correlation between age at diagnosis and $\Delta F 508$ status, ${ }^{56}$ nor did we find an association between $\Delta \mathrm{F} 508$ status and colonisation with Pseudomonas species, which again is different from other surveys. ${ }^{67}$ As expected, patients with moderate to severe chest disease had a significantly higher incidence of Pseudomonas species infection, whether they carried $\Delta$ F508 $(++)$ or $(+-)$ genotypes, compared with those with mild chest disease.

This study has shown that patients heterozygous for the $621+\mathrm{IG}>\mathrm{T}$ mutation, which has a high frequency among Welsh patients (Cheadle et al, personal communication), may have a predisposition to severe chest disease. Although total numbers were small, three out of five patients with $621+\mathrm{IG}>\mathrm{T} / \Delta \mathrm{F} 508$ genotype, aged 15 to 20 years, had an FEV $<50 \%$ predicted, compared with two out of eight patients who were $\Delta F 508$ homozygous positive in the same age group. Among the total of 77 patients who had pulmonary function tests, 15 patients had an $\mathrm{FEV}_{1} \%<50 \%$ of predicted, of whom five were heterozygous for $621+$ IG $>$ T mutation. This apparent predisposition has not been reported before.

There is considerable evidence that $\mathrm{CF}$ patients carrying the R117H mutation, even in single copy, have milder disease. ${ }^{1011}$ It may be relevant that one of our sib pairs with this mutation was diagnosed late (at 6 and 15 years) and that the older of the younger pair was recognised at 2 years, when his younger sister was positive on neonatal screening. Owing to the late diagnosis of the older pair (with absence of specific treatment for CF before this) and the youth of the younger pair, we are unable to advance the case that these four patients who are heterozygous for the $\mathrm{R} 117 \mathrm{H}$ mutation are definitely 'mild', but they would seem to be so.

A longitudinal study over several years to follow up patients of different genotypes should be more informative than the present cross sectional one.

We should like to thank Dr M Alfaham for his clinical contribution to this research; Drs I 
Campbell, $\mathbf{R}$ Prosser, and other clinicians for allowing us to study their patients; and Mrs J Myring for her laboratory assistance. This work was supported for one year by the Joseph Levi Charitable Foundation.

1 Goodchild MC, Dodge JA. Cystic fibrosis: manual of diagnosis and management. 2nd ed. London: Bailliere Tindall, 1982.

2 Kerem BS, Rommens JM, Buchanan JA, et al. Identification of the cystic fibrosis gene: genetic analysis. Science 1989;245:1073-80.

3 Rommens JM, Iannuzzi MC, Kerem BS, et al. Identification of the cystic fibrosis gene: chromosome walking and

4 Riordan JR, Rommens JM, Kerem BS, et al. Identification of the cystic fibrosis gene: cloning and characterization of complementary DNA. Science 1989;245:1066-73.

5 Kerem E, Corey M, Kerem BS, et al. The relation between genotype and phenotype in cystic fibrosis-analysis of the most common mutation (delta F508). N Engl $f$ Med most common muta

6 Johansen HK, Nir M, Hoiby N, et al. Severity of cystic fibrosis in patients homozygous and heterozygous fo delta F508 mutation. Lancet 1991;337:631-4.

7 Santis G, Osborne L, Knight RA, et al. Linked marke haplotypes and the delta F508 mutation in adults with mild pulmonary disease and cystic fibrosis. Lance 1990;335:1426-9.

8 Santis G, Osborne L, Knight RA, et al. Independent genetic determinants of pancreatic and pulmonary status in cystic fibrosis. Lancet 1990;336:1081-4.

9 Chrispin AR, Norman AP. The systematic evaluation of the chest radiograph in cystic fibrosis. Pediatr Radiol 1974;2:101-6.

10 Dean $M$, White MB, Amos J, et al. Multiple mutations in highly conserved residues are found in mildly affected Cell 1990;61:863-70.

11 Keston M, McIntosh I, Brock DJH, Marshall TG, Greening AP. Comparison of clinical phenotype and mutation at cystic fibrosis locus. Am Rev Respir Dis 1991;143:605A. 